\title{
A abordagem dos gêneros do discurso em um livro didático de alemão como língua estrangeira para iniciantes
}

[The speech genres approach in a textbook of German as a foreign language for beginners ] http://dx.doi.org/10.1590/1982-88371826188122

\author{
Bernardo Kolling Limberger ${ }^{1}$ \\ Vanessa Fonseca Barbosa ${ }^{2}$
}

\begin{abstract}
Teaching based on texts and textual diversity has been receiving increasing space in classrooms and textbooks. The Bakhtin Circle Theory of speech genres has founded several theories of analysis and it is the starting point of the theories of textual/discourse genres. This theory focuses on the study of discursive materiality in their socio-historical and ideological aspects, also considering the conditions of production and communicative situations. Given these considerations, the aims of this work are to verify the conception of genres in a book of German as a foreign language for beginners: Planet Al and investigate how the activities are addressed in this material. The analysis is qualitative and there is no quantification of genres covered in the textbook. Therefore, three activities were chosen based on three genres, among the most current in the textbook: a telephone conversation, e-mails and a chart. The results show that the textbook aims to address the textual heterogeneity, but it rarely has characteristics related to the conditions of production and the communicative situation.
\end{abstract}

Keywords: Speech genres; Textbook; German; Foreign language.

Resumo: Cada vez mais, o ensino baseado em textos ganha espaço nas salas de aula de línguas e nos livros didáticos. A teoria dos gêneros do discurso, advinda do Círculo de Bakhtin, tem fundamentado diversas análises e é o ponto de partida das teorias de gêneros discursivos e/ou textuais. Essa teoria é centrada no estudo das materialidades discursivas em seus aspectos sóciohistóricos e ideológicos, considerando também as condições de produção e as situações de comunicação dos discursos. Diante de tais considerações, os objetivos deste trabalho são: verificar a concepção de gêneros em um livro didático de alemão como língua estrangeira para iniciantes Planet Al e investigar o modo como as atividades com os gêneros são abordadas nesse material. A análise apresentada neste artigo é qualitativa e não há qualquer quantificação dos gêneros abordados no livro didático. Para tanto, foram escolhidas três propostas de atividades baseadas em três gêneros, entre os mais recorrentes do livro didático: uma conversa telefônica, e-mails e um gráfico. Os resultados das análises demonstram que o livro didático

\footnotetext{
${ }^{1}$ Pontifícia Universidade Católica do Rio Grande do Sul, Faculdade de Letras, Av. Ipiranga, 6681, 90520300, Porto Alegre, RS, Brasil. E-mail: bernardo.limberger@acad.pucrs.br. Pesquisa realizada com bolsa do CNPq.

${ }^{2}$ Pontifícia Universidade Católica do Rio Grande do Sul, Faculdade de Letras, Av. Ipiranga, 6681, 90520300, Porto Alegre, RS, Brasil, E-mail: vanessa.barbosa@acad.pucrs.br. Pesquisa realizada com bolsa do CNPq.
} 
visa abordar a heterogeneidade textual, mas raramente apresenta características relacionadas às condições de produção e à situação de comunicação em que os discursos se instauram.

Palavras-chave: Gêneros do discurso; Livro didático; Alemão; Língua estrangeira.

\section{Introdução}

Frequentemente, devido à diversidade das atividades humanas e ao surgimento ou aprimoramento de ferramentas tecnológicas, surgem novos gêneros do discurso. Considerando os pressupostos de Bakhtin e seu Círculo, a riqueza de gêneros do discurso é tão infinita que qualquer tentativa de quantificá-los se torna inviável, pois as possibilidades da multiforme atividade humana são inesgotáveis.

A diversidade de gêneros do discurso bem como os aspectos sócio-históricos inerentes a eles podem e devem ser contemplados no ensino de línguas, uma vez que os gêneros constituem-se por meio da linguagem concreta e viva, o que permite ao aluno refletir sobre seu funcionamento e compreender as relações de sentido estabelecidas através da linguagem em uso. Assim, o trabalho com os gêneros discursivos possibilita uma mudança de paradigma no ensino de línguas com vista a superar a exclusividade dada na escola, muitas vezes, à gramática normativa e à metalinguagem.

Dessa forma, tanto no ensino de língua materna, quanto no ensino de língua estrangeira (doravante LE) ${ }^{3}$, podem ser apresentados e abordados diversos gêneros, uma vez que é a partir do domínio dos gêneros do discurso que organizamos nossos enunciados a diversos interlocutores com as mais variadas finalidades. Afinal, são os enunciados concretizados em gêneros que orientam nossos projetos de dizer, sejam eles produzidos oralmente ou na forma de textos escritos.

Conforme destacou BAKHTIN (2003: 282) ${ }^{4}$, os gêneros do discurso “[...] nos são dados quase da mesma forma que nos é dada a língua materna", ou seja, as crianças aprendem a sua língua por meio de gêneros do discurso em situações cotidianas, isto é, de “enunciações concretas que nós mesmos ouvimos e nós mesmos reproduzimos na

\footnotetext{
${ }^{3}$ Embora as denominações língua estrangeira, segunda língua e língua adicional coexistam na literatura, opto por língua estrangeira (LE) para fazer menção a uma língua que não é a materna. Essa opção se deve ao uso em alemão de Deutsch als Fremdsprache (alemão como LE), que se refere à aprendizagem de alemão fora da Alemanha. A expressão Deutsch als Zweitsprache (alemão como segunda língua) se refere à aprendizagem de alemão na Alemanha em contexto de imersão.

${ }^{4}$ Essa versão foi escrita em 1952 por Bakhtin. Neste trabalho, citamos a referência da versão traduzida para o português, em 2003.
} 
comunicação discursiva viva com as pessoas que nos rodeiam" (idem). Esses são os gêneros primários, segundo BAKHTIN (2003), aqueles que se formaram nas condições de comunicação discursiva imediata e diferenciam-se dos secundários, os quais são mais complexos.

Então, quando um aluno começa a aprendizagem de uma LE, provavelmente ele não domina a construção composicional dos gêneros na língua que está aprendendo. Por isso, é fundamental que ele seja exposto e estabeleça contato também com gêneros primários da LE que está estudando. Nesse aspecto, os livros didáticos costumam ser grandes aliados no processo de ensino e de aprendizagem de línguas estrangeiras, já que eles comportam espaço para o contato do aluno com uma variedade de gêneros e atividades que podem auxiliá-lo no desenvolvimento das competências linguísticas na língua-alvo.

Todavia, fazer o uso adequado de um trabalho com os gêneros discursivos ainda costuma ser um desafio, o qual não deve ser ignorado pelos autores de livros didáticos. Portanto, os linguistas podem auxiliar na elaboração e/ou na reformulação dos materiais, uma vez que a abordagem focada nos gêneros é desafiadora e mais ou menos recente, como também demonstram os documentos como os PCNs e o Quadro Europeu Comum de Referência para Línguas - QECR (CONSELHO DA EUROPA 2001).

Considerando tais pressupostos, os objetivos deste trabalho são: verificar a concepção de gêneros em um livro didático de alemão como LE para iniciantes, o Planet Al (KOPP/ BÜTTNER 2004) e investigar o modo como as atividades com os gêneros são desenvolvidas no material selecionado. Para tanto, realizamos uma análise qualitativa, baseada nos pressupostos da teoria do Círculo de Bakhtin, de três gêneros que constituem o livro investigado: uma conversa telefônica, e-mails e um gráfico.

Este trabalho se organiza da seguinte forma: primeiramente, no referencial teórico, apresentamos os aspectos principais da concepção de gêneros e outros conceitos a ela intimamente relacionados como, por exemplo, o de enunciado e de esfera ideológica (seção 1.1). Em seguida, discorremos sobre algumas características do livro didático de LE e os gêneros do discurso (seção 1.2). Na seção 1.3, apresentamos algumas diretrizes para o trabalho com livro didático quanto aos gêneros do discurso, que constam nos PCNs (BRASIL 1997; 1998) e no QECR (CONSELHO DA EUROPA 2001). $\mathrm{Na}$ sequência, revisamos alguns estudos de pesquisadores que já fizeram análises dos gêneros em livros didáticos (seção 1.4) voltados ao ensino de LE. Na metodologia, 
apresentamos os critérios de seleção e análise das três propostas de atividade. Por fim, no capítulo 3, expomos as análises das três atividades, reproduzidas em anexos.

\section{Referencial teórico}

\subsection{Gêneros do discurso}

$\mathrm{Na}$ área da Linguística Aplicada, pesquisas sobre os gêneros e principalmente sobre o potencial de transposição didática desse conceito têm sido frequentes. Como nos explica RODRIGUES (2004), tais investigações são impulsionadas pela consolidação da mudança do objeto de ensino e de aprendizagem de línguas. O ensino baseado em textos e na diversidade textual passou a ser mais valorizado. Consequentemente, as várias abordagens sobre o gênero têm surgido, especialmente as que têm como foco os estudos dos gêneros textuais e dos gêneros do discurso.

Segundo RODRIGUES (2004), num olhar mais atento das configurações teóricas e metodológicas, essas expressões podem se mostrar como não equivalentes. RoJO (2005) explica as principais diferenças: a teoria dos gêneros do discurso é centrada essencialmente no estudo das situações de produção dos enunciados ou textos em seus aspectos sócio-históricos, enquanto a teoria dos gêneros textuais é centrada na descrição da composição e da materialidade textual. Ambas as correntes são enraizadas em diferentes releituras de herança bakhtiniana.

Assim, apesar das divergências teóricas e analíticas, os pressupostos sobre gêneros comumente retomam as reflexões trazidas por Bakhtin, no ensaio Os gêneros do discurso, o qual constitui um dos capítulos do livro Estética da criação verbal. No referido texto, Bakhtin conceitua os gêneros como "determinados tipos de enunciados estilísticos, temáticos e composicionais relativamente estáveis” (BAKHTIN 2003: 266). Apesar da concepção bakhtiniana de que cada enunciado é particular e individual, há enunciados que possuem semelhanças entre si, sendo possível a identificação de gêneros do discurso.

Trata-se, portanto, de formas típicas de enunciados, que podem ser reconhecidos como constituintes de determinado gênero discursivo. Conforme explica SouZA (1999), Bakhtin entende o enunciado como concreto, um material individual complexo, fonético, articulado; além disso, é uma parte da realidade social. Todo enunciado é 
composto por uma parte verbal, a palavra, e por uma parte não verbal, que corresponde à situação. BAKHTIN, nesses termos, trouxe a definição de enunciado como a unidade básica e real de análise da linguagem, uma vez que, ao contrário da frase, o "enunciado não é uma unidade convencional, mas uma unidade real, estritamente delimitada pela alternância dos sujeitos falantes, e que termina por uma transferência da palavra ao outro.” (BAKHTIN 2003: 294).

Nesse sentido, o autor define também que "cada enunciado é um elo na corrente complexamente organizada de outros enunciados" (BAKHTIN 2003: 272). Tratar do enunciado enquanto elo permite que se tenha uma visão mais holística do processo de interação verbal, já que presume que se considerem os demais elementos da corrente, os quais, nesse caso, constituem-se, por exemplo, do locutor, do interlocutor, do projeto discursivo realizado etc. Isso demonstra que a abordagem bakhtiniana reflete sobre a língua a partir da relação desta com os outros componentes que a constituem.

Tal reflexão acerca da concepção de linguagem advinda do Círculo de Bakhtin, sobretudo a compreensão dos gêneros do discurso, tem influenciado, segundo MARCUSCHI (2008), outras abordagens do ensino de línguas, especialmente a Escola de Genebra. Isso porque a teoria bakhtiniana fornece subsídios teóricos e metodológicos de ordem macroanalítica e categorias amplas, que podem ser assimiladas por diversas abordagens de forma bastante proveitosa.

A diversidade de gêneros, uma proposta de trabalho recorrente nos manuais e nos livros didáticos, é salientada na perspectiva bakhtiniana:

A riqueza e a diversidade de gêneros do discurso são infinitas porque são inesgotáveis as possibilidades da multiforme atividade humana e porque em cada campo dessa atividade é integral o repertório de gêneros do discurso, que cresce à medida que se desenvolve e se complexifica um determinado campo. Cabe salientar em especial a extrema heterogeneidade dos gêneros do discurso (orais e escritos). (BAKHTIN 2003: 262)

Nesse sentido, há um rico repertório de gêneros que faz parte da vida cotidiana, pois as atividades humanas são multifacetadas. Esse aspecto pode ser contemplado na sala de aula de língua materna e estrangeira já que "o querer dizer do locutor se realiza acima de tudo na escolha de um gênero do discurso" (BAKHTIN 2003: 301), sendo essa seleção que permite, então, que sejamos proficientes nas múltiplas situações reais de utilização da linguagem, de realização dos projetos enunciativos do locutor. Após tal escolha, "o intuito discursivo do locutor, sem que este renuncie à sua individualidade e à sua 
subjetividade, adapta-se e ajusta-se ao gênero escolhido, compõe-se e desenvolve-se na forma do gênero determinado" (idem).

Bakhtin salienta, ainda, que não se deve minimizar essa heterogeneidade e a dificuldade de definir a natureza geral do enunciado. Por essa razão, é importante atentar para a diferença entre gêneros discursivos primários (simples) e secundários (complexos). Segundo Bakhtin, "os gêneros discursivos primários se formaram nas condições de comunicação discursiva imediata". Já os gêneros secundários "surgem nas condições de um convívio cultural mais complexo e relativamente muito desenvolvido e organizado [...]. No processo de sua formação, eles incorporam e reelaboram diversos gêneros primários" (BAKHTIN 2003: 263). Os gêneros primários seriam constituídos pela comunicação verbal cotidiana, enquanto os secundários seriam mais complexos, como os romances, dramas, artigos científicos, reportagens, entre outros. Os gêneros primários são mais livres e mais criativos do que os secundários, porque aqueles permitem maior reformulação.

Nesse sentido, pode haver mudanças nos gêneros, que são refletidas e refratadas por mudanças na vida social. Segundo BAKHTIN (2003: 268), “os gêneros do discurso refletem de modo mais imediato, preciso e flexível todas as mudanças que transcorrem na vida social [...], são correias de transmissão entre a história da sociedade e a história da linguagem." Por esse motivo, podemos verificar, por exemplo, transformações atuais como a da carta pessoal, que raramente é escrita, devido à disponibilidade dos meios de comunicação que possibilitam o envio digital de e-mails. Logo, com o surgimento de recursos tecnológicos, os "velhos" gêneros se transformaram e alguns se tornaram obsoletos.

Conforme destacado, Bakhtin defende que o uso da língua acontece em forma de enunciados concretos e únicos, proferidos pelos integrantes de uma ou de outra esfera da atividade humana. "Os enunciados refletem as condições específicas e as finalidades de cada referido campo não só por seu conteúdo (temático) e pelo estilo da linguagem [...], mas acima de tudo, pela sua construção composicional” (BAKHTIN 2003: 261). Assim, quanto à arquitetônica dos gêneros do discurso, Bakhtin nos explica, no capítulo Os gêneros do discurso, que o estilo está ligado ao enunciado e às formas típicas de enunciado e é individual (tipos de acabamento, tipos de acordo com a relação entre falante com os participantes da comunicação discursiva). 
Tratar das considerações traçadas pelos pensadores do Círculo de Bakhtin exige destacar a íntima relação entre os vários conceitos advindos desse grupo, já que a reflexão por eles desenvolvida não se dá de modo estanque, tampouco os conceitos podem ser tomados isoladamente. Fazemos tal ressalva para mostrar que intimamente relacionado aos gêneros do discurso estão também as compreensões de signo e palavra. BAKHTIN/VOLOCHÍNOV (2004: 32) ${ }^{5}$ afirmam que todo o signo é ideológico, ele "[...] não existe apenas como parte de uma realidade; ele reflete e refrata uma outra. Ele pode distorcer essa realidade, ser-lhe fiel, ou apreendê-la de um ponto de vista específico, etc.”; isso demonstra que não há signo neutro.

Nessa perspectiva, BAKHTIN/VolochínOV (2004: 36) elegem a palavra como "fenômeno ideológico por excelência", ou seja, como a materialização do signo ideológico, já que "a palavra é o modo mais puro e sensível de relação social” (idem). Admitir a palavra como signo ideológico e levar tal consideração para o ensino de língua, no caso do ensino de gêneros, implica necessariamente tratar da constituição de sentidos estabelecidos na linguagem, superando o paradigma tradicional de apenas identificar os fenômenos gramaticais e tomar a língua como objeto de nomeação do mundo.

Outra noção essencial que tem relação com os gêneros do discurso é a de esfera (ideológica). Segundo BRAIT (2012), os aspectos linguísticos, a forma, o conteúdo semântico, não podem ser desvinculados de outro aspecto essencial à concepção de gênero, a esfera, que envolve e constitui a produção, circulação e recepção de um gênero, constituindo sua relação com a vida, no sentido cultural e social.

Assim, o caráter dialógico, segundo a perspectiva bakhtiniana, está sempre presente na linguagem. Por mais aparentemente monológico que seja o enunciado, ele não deixa de ser, em certa medida, uma resposta a tudo o que fora dito sobre determinado objeto, determinada questão etc. Todo enunciado é, portanto, uma resposta a outros enunciados (BAKHTIN 2003) e possibilita novas respostas. Em sala de aula, os textos também podem possibilitar a reflexão ao caráter intimamente dialógico da linguagem. Esse aspecto perpassa toda a teoria do Círculo de Bakhtin e caracteriza o dialogismo:

\footnotetext{
${ }^{5}$ Essa versão baseou-se na tradução francesa de Marxismo e Filosofia da Linguagem, em 1977, a qual fora publicada entre os anos de 1929/1930 em Leningrado. Neste trabalho, citamos a referência da versão traduzida para o português, em 2004.
} 
O ouvinte, ao perceber e compreender o significado (linguístico) do discurso, ocupa simultaneamente em relação a ele uma ativa posição responsiva: concorda ou discorda com ele (total ou parcialmente), completa-o, aplica-o, prepara-se para usá-lo etc. [...] toda compreensão é prenhe de resposta, e nessa ou naquela forma a gera obrigatoriamente: o ouvinte se torna falante [...]. Cada enunciado é pleno de ecos e ressonâncias de outros enunciados com os quais está ligado pela identidade da esfera de comunicação discursiva (BAKHTIN 2003: 275-297).

Conforme mostram os teóricos, a língua se concretiza nesse processo dialógico ininterrupto. Bakhtin acrescenta, dizendo que a vontade discursiva individual do falante se manifesta na escolha de um determinado gênero e, ainda, na sua entonação expressiva. Segundo BRAIT (2012), o gênero é o conjunto dos modos de orientação coletiva dentro da realidade; por meio do gênero é possível compreender novos aspectos da realidade ou a realidade social de sua realização no processo da comunicação.

Desse modo, uma abordagem centrada nos gêneros do discurso pode ser benéfica no ensino de língua por permitir considerar os aspectos sociais, históricos e culturais, sempre relacionados ao uso da linguagem. Em outras palavras, tratar da linguagem considerada nas suas mais diversas formas significa promover no ensino de línguas reflexões que permitem auxiliar os alunos no desenvolvimento de suas competências comunicativas. Assim, eles podem compreender as relações de sentidos engendrados na linguagem através dos gêneros em que ela se materializa.

\section{$1.2 \bigcirc$ livro didático de LE e os gêneros do discurso}

Apesar das evoluções tecnológicas, o livro didático desempenha um papel fundamental na sala de aula de LE. Segundo MAIJALA (2007), o material didático em geral é aplicável de diversas formas, pode ser utilizado em distintos lugares e normalmente oferece uma abordagem abrangente e estruturada da língua.

MARCUSCHI (2008) considera o livro didático como um suporte textual, uma vez que contém muitos gêneros. A incorporação dos gêneros pelo livro didático não muda esses gêneros em suas identidades, embora lhes dê outra funcionalidade. $\mathrm{O}$ autor acredita que Bakhtin teria caracterizado o livro didático como um conjunto de gêneros, situados na esfera do discurso pedagógico. Podemos afirmar também que esse suporte contém gêneros específicos da esfera pedagógica, como a explicação textual, os exercícios escolares, a redação, as instruções de produção textual e muitos outros. 
Quanto à constituição dos textos que compõem os livros didáticos, vários manuais de LE consideram que os textos ideais deveriam ser aqueles considerados autênticos. Maijala (2007) salienta que um texto autêntico nos livros didáticos de LE significa uma simulação de legitimidade, ou seja, da realidade da língua-alvo. Assim, os textos autênticos seriam recortes de textos reais que circularam em determinado suporte da língua-alvo com vistas a atender algum projeto discursivo de variados interlocutores como, por exemplo, notícias de jornais, revistas, propagandas etc. Como argumentam JERÔNIMO, BARBOZA E RIBEIRO (2013), o contato com textos autênticos oferece modelos de uso real aos aprendizes, o que, por sua vez, facilita o processo de contato com a LE e a sua compreensão.

No entanto, o que se observa na maior parte dos livros didáticos de LE, principalmente nas aulas para iniciantes, é que os textos são concebidos para fins didáticos, ou seja, são simulacros linguísticos, o que dificulta atingir essa legitimidade. Por esse motivo, MajJala (2007: 549) argumenta que os textos podem parecer artificiais, o que, consequentemente, pode dificultar o processo de aprendizagem da língua-alvo, haja vista que o aluno tem pouco ou praticamente nenhuma exposição a situações reais de utilização da linguagem.

Quanto à abordagem dos gêneros em sala de aula, cabe destacar que ela é complexa e constitui ainda um desafio para o trabalho dos professores, apesar de terem conquistado espaço nos livros didáticos. RoJo (2005) orienta que parece mais útil e necessário explorar com os alunos as características das situações de enunciação relacionadas às marcas linguísticas que deixam como traços nos textos - do que fazermos análises completas e exaustivas dos textos, introduzindo uma nova metalinguagem. Todavia, uma dificuldade da abordagem sócio-histórica nos livros didáticos é manter a durabilidade do conteúdo do material por certo período de tempo.

Segundo MaiJALa (2007: 549), quanto mais um livro se aproxima das tendências atuais, mais rápido ele se desatualiza. Isso significa que o professor precisa auxiliar os alunos a recuperar a situação de comunicação e as condições de produção nas quais determinado gênero está inserido, para o bom desenvolvimento de um trabalho com os gêneros, o que, por sua vez, evidencia os seus desafios. Caso esse caráter sócio-histórico não for recuperado, pode-se cair, por exemplo, no equívoco de propor atividades com os gêneros apenas como pretexto para a continuidade de um ensino gramatical/normativo. 
Na opinião de ANTUNES (2010: 26), em um ensino gramatical, os professores privilegiam fragmentos dos textos, sem referência ao todo do qual são partes significativas. Logo, selecionar um gênero para o trabalho na sala de aula e considerá-lo como um pretexto para o ensino somente de questões lexicais e gramaticais pode não proporcionar o desenvolvimento da competência comunicativa do aluno. É necessário desenvolver uma abordagem que possibilite ao aluno compreender as particularidades de organização da linguagem nas suas mais diversas formas, materializadas em gêneros discursivos diversos. Em outras palavras, o ensino baseado em gêneros possibilita auxiliar os estudantes a tratar de questões autênticas de utilização da linguagem, compreendendo o seu papel na construção de sentidos e, assim, auxiliando os alunos no desenvolvimento de suas competências comunicativas.

\subsection{Diretrizes para o trabalho com o livro didático quanto aos gêneros do discurso}

A abordagem para os textos no livro didático selecionado neste trabalho, Planet 1, é orientada pelo QECR (CONSELHO DA EUROPA 2001: 136). Conforme as diretrizes, o termo 'texto' "denomina qualquer referência discursiva, oral ou escrita. [...] Assim, não pode existir acto (sic) de comunicação linguística sem um texto”. O texto pode ser considerado como um produto acabado ou um produto em processo de elaboração, ele estaria no centro do ato de comunicação linguística. Além disso, segundo o documento, os textos podem ser classificados em diferentes tipos, pertencendo a diferentes gêneros, que têm relação com as diferenças de suporte, de finalidade, função, contexto, organização e apresentação entre os textos. Ademais, os textos devem provocar algum tipo de resposta.

No Brasil, por sua vez, os Parâmetros Curriculares Nacionais (PCNs) norteiam o ensino. Nos PCNs de língua portuguesa para ensino fundamental há orientações explícitas sobre os gêneros. Estes, conforme o documento, devem orientar o ensino, uma vez que "tudo se organiza dentro de um determinado gênero. Os vários gêneros existentes, por sua vez, constituem formas relativamente estáveis de enunciados, disponíveis na cultura” (PCNs 1997: 23). A referência, no documento, é a Bakhtin e o texto tomado, portanto, como objeto de ensino. 
Em contrapartida, como se pode verificar, nos PCNs de LE, não há menção a gêneros, somente a textos variados ou a tipos de texto, cuja compreensão também decorre dos elementos extra-verbais (ilustrações, tabelas, gráficos etc.). Conforme o documento, "a determinação dos conteúdos referentes a tipos de texto (orais e escritos) se pauta por tipos com os quais os alunos nessa faixa etária estão mais familiarizados como usuários de sua língua materna" (PCNs 1997: 74).

Podemos verificar nos documentos uma falta de consenso entre o documento europeu e o brasileiro, principalmente com relação à terminologia. No QECR, utilizamse os termos tipo e gênero indiscriminadamente; enquanto no documento brasileiro, os gêneros somente aparecem no documento para a língua portuguesa. Contudo, vimos a necessidade de uma congruência teórica entre os materiais, tendo em vista que a pesquisa sobre gêneros evoluiu muito nos últimos 20 anos e precisa ser incorporada nos documentos oficiais, para que os documentos possam orientar os professores quanto ao trabalho em sala de aula.

Outro aspecto interessante observado é que o QECR incentiva que os textos possibilitem respostas, o que se aproxima do caráter dialógico da linguagem, de Bakhtin. Ademais, em ambos os documentos, os aspectos extraverbais devem ser considerados no ensino.

\subsection{A abordagem dos gêneros em livros didáticos de LE}

Considerando a importância da abordagem dos gêneros em sala de aula, alguns pesquisadores já analisaram livros didáticos. STRIQUER (2009), por exemplo, ao analisar um livro de português como L1, constatou que, devido à prevalência do trabalho com o tema, houve um desprezo às outras propriedades do gênero do discurso, isto é, as propriedades estilísticas e as formais. Além disso, os elementos constitutivos do gênero foram superficialmente abordados, devido ao foco nos fatores gramaticais e de compreensão e interpretação do texto.

ARANTES (2011) realizou uma análise qualitativa dos gêneros textuais num livro didático de alemão como LE. A autora selecionou alguns gêneros, como a carta pessoal, um cartão postal e uma reportagem. A abordagem didática de alguns gêneros não contempla a referência ao contexto pessoal, como na carta pessoal, na qual falta a 
referência ao uso de vocativos e da forma como se deve finalizá-la. Dessa forma, como sugere a autora, é necessário que o professor intervenha, de modo que as características de cada gênero sejam preservadas e que o aluno se aproprie adequadamente do gênero dentro da cultura da LE.

No caso do cartão postal investigado na pesquisa citada, o aluno deveria escrever um cartão para um destinatário inventado e desconhecido, o que não configura uma abordagem dos gêneros do ponto de vista discursivo. A simples substituição de termos, como, por exemplo, adjetivos, advérbios, cidades e dias da semana na escrita do cartão pode não desenvolver a capacidade de escrita do gênero dentro de um contexto social e não estimular a reflexão sobre o modo de constituir os sentidos por meio dos gêneros discursivos, como, por exemplo, o grau de intimidade dos interlocutores e a situação em que se encontram. Outro gênero analisado pela autora é ofertas de supermercado. Com relação a este gênero, ela problematizou a questão da autenticidade, já que a adaptação desse gênero para o livro didático contemplou somente a apresentação do vocabulário e não utilizou o suporte folder.

JERÔNIMO, BARBOZA E RIBEIRO (2013), ao analisarem coleções de livros didáticos de inglês como LE, constataram diversidade de gêneros, mas muito deles foram adaptados para o livro didático, e o foco da abordagem foi a forma linguística. Entretanto, houve também textos mais aproximados aos autênticos, com uma preocupação maior na formação do leitor e em proporcionar o contato com a língua real. O conhecimento dos aspectos socioculturais e históricos da LE aprendida aparece como algo secundário. Aqueles com conteúdo informativo (reportagens, folhetos informativos, entre outros) predominaram.

Os três trabalhos apontaram para lacunas na abordagem dos gêneros nos livros didáticos de português, de alemão e de inglês como LE: por exemplo, o desprezo às propriedades extraverbais do gênero do discurso, o predomínio de atividades de substituição de termos e a preocupação somente com a forma linguística. Os livros de português e de inglês foram analisados de acordo com a teoria dos gêneros do discurso, ao passo que o livro didático de alemão foi analisado de acordo com a teoria dos gêneros textuais. Neste trabalho, analisamos propostas de exercícios de alemão como LE com base na teoria dos gêneros do discurso, com vistas a estabelecer um diálogo com estudos já realizados, bem como a contribuir com pesquisas futuras que buscam melhor compreender o potencial dos gêneros do discurso no ensino de línguas. 


\section{Metodologia: seleção e análise}

O livro didático eleito para a análise deste trabalho é o Planet Al - Deutsch für Jugendliche, de autoria de Gabriele Kopp e Siegfried Büttner, lançado em 2004 pela Editora Hueber. A escolha do livro se deve à sua ampla utilização no Brasil e à proposta, isto é, uma abordagem comunicativa, pautada nos gêneros. O livro é destinado a adolescentes de 11 a 15 anos sem conhecimentos prévios de alemão como LE. O objetivo do livro é transmitir uma língua autêntica e aproximada à realidade dos jovens. O livro completo é composto por três volumes: a) Planet 1 - nível A1; b) Planet 2 nível A2; c) Planet 3 - nível B1. Cada volume é composto pelos seguintes materiais complementares: livro de exercícios, textos-áudio e manual do professor. O livro é destinado a iniciantes, e foi escolhido a fim de verificar se (e como) a proposta de heterogeneidade textual é seguida, apesar da limitação linguística dos aprendizes.

A análise é baseada na teoria do Círculo de Bakhtin sobre os gêneros do discurso, anteriormente exposta. Essa teoria assume uma metodologia essencialmente qualitativa. Por esse motivo, não quantificamos os gêneros abordados no livro didático, limitamos a análise a três propostas de atividades baseadas em três gêneros, entre os mais recorrentes do livro didático: uma conversa telefônica, e-mails e um gráfico. As três propostas de atividades constituem-se gêneros, por possuirem tipos relativamente estáveis de enunciados (BAKHTIN 2003). A esses três gêneros estão relacionados outros, que são dependentes do texto-base.

Examinamos os enunciados na materialidade de um gênero discursivo, considerando os aspectos sugeridos pela ordem metodológica de BAKHTIN/VOLOCHINOV (2004: 124): as formas e os tipos de interação verbal, com relação às esferas sociais; os enunciados, com relação aos gêneros e as formas da língua.

Desse modo, a análise bakhtiniana, conforme explica RoJO (2005), não configura análise exaustiva das propriedades do texto e de suas formas de composição (gramática) - buscando as invariantes do gênero -, mas uma descrição do texto/enunciado pertencente ao gênero ligada sobretudo às maneiras (inclusive linguísticas) de configurar a significação. 


\section{A abordagem dos gêneros do discurso no livro didático de alemão como LE para iniciantes}

O manual do professor menciona as Textsorten, os gêneros textuais. Conforme explicam KOPP e BÜTTNER (2004b: 6), o ponto de partida é a diversidade dos textos que aparecem na vida real, como, por exemplo, diálogos, entrevistas, avisos, cartazes, artigos de jornal, entre outros, o que é também sugerido nos documentos oficiais anteriormente analisados (PCNs e QECR).

Os gêneros diversificados formam a base para o desenvolvimento de estratégias de compreensão oral e leitora no livro didático. O aluno deve aprender a aproveitar informações prévias na forma de ruídos, figuras ou títulos, para depreender o conteúdo do texto. Desse modo, ele pode relacionar o texto a experiências prévias, que podem ajudá-lo a entendê-lo. O princípio norteador do livro didático é a diversidade de textos; portanto, essa característica deve estar presente também nos níveis iniciais.

A concepção do livro didático Planet Al pautada na diversidade de gêneros parece ter filiação a um dos princípios bakhtinianos que diz respeito à importância do contato com uma variedade de gêneros discursivos, o que tende a auxiliar no desenvolvimento das competências comunicativas dos indivíduos. Desse modo, é de se esperar que o livro didático também aborde essa diversidade, o que efetivamente parece ser cumprido: no Planet Al, há vários gêneros, dentre os quais é possível destacar: páginas da internet, histórias em quadrinhos, tiras, conversas, telefonemas, bilhetes de ingressos para cinema e teatro, poemas, letras de música, entrevistas, e-mails, mensagens de SMS, infográficos, anotações de caderno, cartazes, notícias, diários e gráficos.

A seguir, apresentamos a análise das três propostas de atividades de compreensão textual: primeiramente, a análise das atividades sobre a conversa telefônica, em seguida, sobre os e-mails e, por fim, sobre o gráfico. 


\subsection{Atividade 1: uma conversa telefônica}

A proposta de compreensão do gênero conversa telefônica e os respectivos exercícios (Anexo 1) aparecem com frequência no livro Planet A1. Acredita-se que isso ocorre porque o gênero é muito apropriado ao trabalho com a abordagem comunicativa de ensino de línguas.

$\mathrm{Na}$ proposta selecionada, os alunos escutam uma conversa telefônica (com entonação) e podem ler a transcrição ao mesmo tempo. Nesse bate-papo, Uli convida o seu amigo Manuel para ir ao cinema, mas Manuel recusa, porque precisa fazer as tarefas domésticas. Uli insiste, dizendo que o filme é muito bom e só passará no dia de hoje. Manuel recusa novamente, e Uli diz que o seu amigo é do contra. Por fim, Manuel aceita ir ao cinema, mas diz que precisa chegar em casa às 5 horas. Depois desse diálogo, os alunos são solicitados a substituir as falas demarcadas por outras, gerando novas conversas (atividade $a$ ). No fim, os alunos, em duplas, formulam novos diálogos livremente (atividade $b$ ).

As sugestões que KOPP e BÜTTNER (2004b) fazem no manual do professor para o ensino do gênero e da língua com base nessa proposta se referem a escutar a conversa telefônica, repetir, exercitar, substituir as frases sinalizadas e realizar conversas telefônicas com os colegas. Além disso, os autores sugerem que o professor explique o sentido das expressões idiomáticas, comuns a gêneros primários (BAKHTIN 2003) como a conversa telefônica: Nun hab dich nicht so! e Sei doch kein Frosch!

Inicialmente, cabe destacar que a seleção de um gênero primário para aprendizes iniciantes de uma LE pode ser algo bastante positivo, tendo em vista a exposição desses alunos a situações cotidianas em que se manifestam gêneros que realmente fazem parte da vida dos falantes da língua-alvo como é o caso, por exemplo, de uma conversa telefônica. Todavia, como se pode perceber, a proposta, inserida na esfera pedagógica, parece estar desvinculada de um contexto sócio-histórico determinado, o que demonstra que o trabalho com o gênero, considerando os pressupostos do Círculo de Bakhtin, não é satisfatoriamente desenvolvido. Ademais, os enunciados trocados entre os interlocutores são tomados como palavras isoladas a serem repetidas mecanicamente pelos aprendizes da LE.

Conforme salienta BAKHTIN (2003: 291), quando se destaca o trabalho com os gêneros e, mais especificamente, com os enunciados que os constituem, nunca se está 
apenas diante de palavras isoladas, mas sim "[...] de determinada realidade concreta em condições igualmente reais de comunicação". Embora a enunciação seja do âmbito do irrepetível/irrecuperável, para compreender as relações de sentido engendradas pela linguagem concretizada em gêneros, é importante que se ofereçam pistas para que as situações de linguagem analisadas possam se aproximar de eventos reais da língua, em que a sua dinamicidade e vivacidade não se perca. No entanto, no caso da atividade analisada, temos uma conversa telefônica isolada e a única pista que permite inferir que participam da interação dois jovens alemães está no início da interação, em que um dos participantes fala o seu nome (Manuel Altmann).

$\mathrm{Na}$ esfera pedagógica, principalmente com relação à LE, os textos são frequentemente adaptados, com a finalidade de abordar aspectos gramaticais específicos da língua que está sendo aprendida. Como postula MARCUSCHI (2008), um livro não muda o gênero em sua identidade, mas lhe dá outra funcionalidade, o que também acontece com o Planet 1. JERÔNIMO, BARBOZA E RIBEIRO (2013) chegaram à mesma conclusão em sua análise quanto ao ensino de inglês como LE: o foco das atividades do material didático que investigaram parecia estar, muitas vezes, na forma linguística. Os enunciados fazem parte da realidade social de ensino de LE, na qual essas características de apagamento das questões históricas e socioculturais são frequentes.

No exemplo ora analisado, a partir do gênero conversa telefônica, há atividades que remetem à criação de outras conversas. Na primeira atividade (a), os alunos precisam somente substituir os trechos assinalados por outros. Essa atividade de substituição não gera necessariamente uma atitude ativa e responsiva, na qual o ouvinte se torna falante, porque as frases estão prontas. O ouvinte não ocupa, portanto, a ativa posição responsiva descrita por BAKHTIN (2003), porque não produz novos enunciados a partir dos anteriormente proferidos; ele simplesmente os substitui.

A atividade de substituição pode ser importante para que os alunos aprendam como esse gênero primário se estrutura em alemão. Esses enunciados refletem, portanto, a finalidade dos textos da esfera pedagógica, principalmente pelo que Bakhtin denomina estilo e pela construção composicional. No entanto, o gênero aparece com frequência no livro didático, e a atividade de substituição poderia ter sido evitada, porque os alunos já teriam condições de ter dominado as suas características composicionais. Além disso, como argumenta ARANTES (2011), a simples substituição de expressões ou frases pode não desenvolver a capacidade de escrita do gênero dentro de um contexto social. 
Por outro lado, na atividade $b$, uma atitude responsiva é solicitada. O diálogo apresentado no livro gera outros enunciados, ou seja, outros diálogos que podem ser inseridos, efetivamente, numa situação de comunicação. Desse modo, o gênero em análise está ligado a outros enunciados, pela identidade da esfera de comunicação discursiva (BAKHTIN 2003), que é pedagógica e, por isso, os novos diálogos poderiam ser simulações, nas quais os alunos desempenhariam um papel.

O gênero conversa telefônica poderia ser mais bem explorado no livro didático, isto é, poderia estar inserido numa situação de comunicação mais concreta, na qual seriam explicitados o locutor, o interlocutor (fotos poderiam ser colocadas no livro, no lugar de figuras), o local, os números de telefone, as características e as opiniões dos participantes etc. Desse modo, o gênero é isolado da situação de comunicação, o que pode causar dificuldades no momento em que um aprendiz precisar exercitar, por exemplo, sua prática de aplicação da língua na Alemanha. Uma sugestão para melhorar a abordagem seria, se for possível, criar situações de comunicação concretas, com base na conversa apresentada no livro didático.

Um aspecto interessante do gênero primário analisado são as expressões idiomáticas. Os autores do livro didático sugerem trabalhar com o sentido das expressões na dica (Tipp!) disponibilizada no livro: memorize as expressões idiomáticas e as utilize também em outras situações. Esse aspecto estilístico que aparece frequentemente nos gêneros primários é uma boa abordagem que se adequa ao gênero.

\subsection{Atividade 2: e-mails sobre café da manhã}

A proposta de trabalho com e-mails sobre o café da manhã consiste na leitura dos textos de três adolescentes de partes do mundo diferentes (Anexo 2). Nos e-mails, os adolescentes contam sobre o café da manhã naqueles países. Depois da leitura, os alunos respondem a perguntas com base nos textos (por exemplo, "O que o menino da Nova Zelândia come no café da manhã?"). Em seguida, os alunos são solicitados a formularem outras perguntas sobre os textos a um colega (atividade $b$ ). Por fim, eles conversam sobre os seus costumes de café da manhã e dos costumes no seu país (atividade $c$ ). No manual do professor, não há muitas sugestões de KOPP E BÜTTNER (2004b) para o ensino do gênero com base nessa proposta de atividade, além das mencionadas no livro-curso. 
Os três e-mails estão apresentados, no livro didático, em caixas de texto. Há um endereço de e-mail e, ao lado, o nome do adolescente que o enviou. Além disso, há o assunto (Betreff). Embora a apresentação do gênero tenha sido alterada, podemos reconhecer a sua identidade, conforme MARCUSCHI (2008). Vemos, nesse caso, que o livro didático apresenta um gênero atual, ao contrário de outros, que ainda insistem em abordar a carta. As mudanças na vida social, que são incorporadas pelos gêneros do discurso (BAKHTIN 2003), podem ser percebidas no livro didático.

Todavia, a mera inseração do gênero no livro didático não é suficiente para garantir o desenvolvimento de um trabalho que proporcione o domínio do gênero $e$ mail. Também é necessário que o tema do gênero faça parte de uma situação concreta de uso da linguagem. No entanto, na proposta de atividade, três adolescentes de diferentes países trocam e-mails para dialogarem sobre o café da manhã. No cotidiano dos adolescentes, essa situação parece ser pouco verossímil e recorrente. Esse simulacro de utilização da linguagem pode ser usado "apenas como abstração e não ser apresentada como fenômeno pleno, concreto e real; caso contrário, ela se transforma em ficção" (BAKHTIN 2003: 273), o que vai de encontro à concepção de ensino baseada em gêneros discursivos.

Além disso, a adaptação desse gênero para o livro didático contemplou somente uma apresentação superficial da situação de produção; por isso, os textos pareceram artificiais (MAIJALA 2007). Da mesma forma que a proposta anterior, esta parece estar desvinculada de um contexto sócio-histórico determinado. As outras características que envolvem um e-mail recebido, como a data, o horário, o e-mail anterior, e todas as informações que constam no computador poderiam constar junto à mensagem de $e$ mail. Da mesma forma que em ARANTES (2011), as características de produção do gênero foram minimizadas. Talvez se as condições de produção dos e-mails fossem apresentadas no livro didático, a durabilidade seria menor, conforme alerta MAIJALA (2007). Por isso, um livro lançado em 2004 pode ser utilizado ainda dez anos depois.

Quanto às atividades $a$ e $b$ da proposta, elas podem ser cumpridas somente com a cópia de informações dos textos. Entretanto, formular perguntas abertas (Ja/NeinFragen) é uma importante habilidade na LE, que deve ser sempre realizada. Poderia ser mais produtivo para o ensino da LE que essas perguntas fossem formuladas com base em informações pessoais e opiniões. Por outro lado, uma atividade dialógica, baseada nos $e$-mails, pode ser conduzida (atividade $c$ ). 
Limberger / Barbosa - Gêneros do discurso no livro didático

Para BAKHTIN (2003), todo enunciado possibilita novas respostas, e a aula somente será dialógica se os aprendizes tiverem a oportunidade de fornecer uma resposta a qualquer texto, como também é incentivado pelo QECR (CONSELHO DA EUROPA 2001). Desse modo, os gêneros estão intimamente relacionados, como elos na cadeia verbal: "cada enunciado é um elo na corrente complexamente organizada de outros enunciados" (BAKHTIN 2003: 272), o que é oportunizado pela resposta aos textos dos adolescentes de outros países. Entretanto, o trabalho com o gênero e-mail poderia dar maior papel também ao destinatário, fazendo com que os alunos refletissem sobre o modo como a organização do gênero está intimamente relacionada com o interlocutor presumido pelo locutor, pois "a escolha de todos os recursos linguísticos é feita pelo falante sob maior ou menor influência do destinatário e da sua resposta antecipada” (BAKHTIN 2003: 306).

\subsection{Atividade 3: gráfico sobre tempo livre}

A terceira proposta selecionada consiste no trabalho com um gráfico das atividades do tempo livre de jovens alemães. Os alunos são solicitados a ler o gráfico e a responder a perguntas sobre as atividades preferidas de tempo livre dos adolescentes alemães (Anexo 3). O gráfico é dividido em duas partes: as atividades do tempo livre de meninas e de meninos. Na atividade $a$, os alunos descrevem o gráfico com base nas estruturas fornecidas. $\mathrm{Na}$ atividade $b$, os alunos respondem questões de análise do gráfico, como: (1) o que as meninas gostam tanto de fazer quanto os meninos? (2) O que as meninas gostam muito de fazer, e os meninos nem tanto? (3) O que os meninos gostam muito de fazer, e as meninas nem tanto? Na atividade $c$, os alunos são solicitados a conversar com o seu colega, comparando os meninos e as meninas com mais detalhes. Na atividade $d$, a turma faz uma enquete e depois confecciona um gráfico com os resultados da turma. Os autores sugerem no manual do professor (KOPP/ BÜTTNER 2004b: 70), além das atividades propostas no livro-curso, fazer uma atividade de construção de gráfico com outras turmas da escola e comparar com os resultados do gráfico.

Diferentemente do que aconteceu nas atividades analisadas anteriormente, a situação de comunicação original parece ter sido mantida nesse gráfico, uma vez o gráfico publicado no site http://www.politikundunterricht.de/ foi reproduzido na íntegra. Informações como fonte, ano (2002), título, figuras, logotipo da empresa que fez o gráfico podem ser visualizadas pelos alunos. Desse modo, os autores do livro didáticos 
adaptaram a finalidade de um texto da esfera midiática para a esfera pedagógica, fornecendo propostas de atividade de descrição e produção do gráfico. Depois de pronto, este poderia ser compartilhado na internet ou na escola. Esse é um exemplo de trabalho com gêneros do discurso no qual foram mantidas os aspectos sócio-históricos, sem que o conteúdo ficasse muito desatualizado.

Por outro lado, podemos afirmar que as atividades $a, b$ e $c$ poderiam ser mais desenvolvidas para se aproximarem da abordagem dialógica dos gêneros discursivos, tendo em vista que tiveram por foco o trabalho com a habilidade de escrita com base no texto. Confome destaca BAKHTIN (2003: 271), “o ouvinte, ao perceber e compreender o significado (linguístico) do discurso; ocupa em relação a ele uma ativa posição responsiva", a qual permite estabelecer o processo dialógico na cadeia ininterrupta da comunicação verbal, tendo em vista que o interlocutor se coloca nessa posição respondente, complementando o discurso, axiologicamente.

No entanto, no caso da atividade com os gráficos ora analisada, percebemos uma lacuna nessa tomada de posição do interlocutor, já que, por meio das questões descritas, o aluno não precisa acrescentar informações, concordar ou discordar, falar a sua opinião, posicionar-se ativamente no processo comunicativo. Ocorre uma mudança significativa se comparada à atividade $d$, na proposta de criação de outro gráfico, por meio da qual os alunos fornecem uma resposta ao gráfico, dialogando com os colegas, isto é, enfatiza-se esse poder dialógico da linguagem, que sempre se direciona a um outro capaz de atribuir-lhe sentidos. Desse modo, se o aprendiz compreendeu adequadamente o texto, nesse último item, ele pode tomar uma ativa posição responsiva (BAKHTIN 2003).

Como podemos verificar, o trabalho com os gêneros discursivos é ainda um desafio aos autores de livros didáticos e também aos professores de línguas, já que exige o desenvolvimento de atividades que não ignorem o caráter dinâmico e vivo da linguagem que os constitui, embora, é evidente, para a constituição dos materiais didáticos, precisemos sempre trabalhar com recortes desse objeto tão rico. É justamente ao cuidado com esse recorte que deve se voltar a atenção dos autores dos livros didáticos e também dos professores durante a aplicação do material em sala de aula, para que o trabalho com os gêneros não ignore que a linguagem acompanha $o$ desenvolvimento social e se (trans)forma sempre em meio a inúmeros fatores extraverbais: condições sócio-históricas e ideológicas em que se manifesta, relacionada 
intimamente ao querer dizer do locutor, aos interlocutores etc. Por isso, a necessidade de pesquisas nessa área com vistas a auxiliar o processo educacional e, principalmente, a inserir os alunos em um processo de trabalho com a linguagem em que esta não se prive de algumas das suas características mais essenciais e que devem ser consideradas no ensino, isto é, sua essência carregada "de personalidade, de cor e de expressividade" (BAKHTIN 2013: 41).

\section{Considerações finais}

Neste trabalho, podemos verificar que a tendência de se abordar a LE com base nos gêneros foi seguida também pelo livro didático Planet Al, o que está de acordo com os documentos oficiais analisados (PCNs e QECR). No entanto, a abordagem de gêneros do discurso nem sempre é simples de ser conduzida, devido aos aspectos sóciohistóricos, que podem prejudicar a durabilidade do conteúdo do material didático. $\mathrm{O}$ livro Planet Al parece estar mais fundamentado nos gêneros textuais (Textsorten). A abordagem do livro parece se basear mais na descrição da composição e materialidade textual (RoJO 2005).

No que concerne ao primeiro aspecto investigado, a concepção de gêneros no livro didático Planet A1, o ponto de partida é a diversidade dos textos que aparecem na vida real. Esse aspecto é realmente abordado no livro, mesmo que ele seja destinado para iniciantes na aprendizagem de alemão. A diversidade de gêneros parece ter filiação bakhtiniana, que salienta a diversidade de gêneros do discurso (orais e escritos), ligada à diversidade de possibilidades da atividade humana. É muito importante que essa característica não seja negligenciada por nenhum livro didático, seja ele baseado em gêneros textuais ou em gêneros discursivos.

Os gêneros do discurso podem potencializar a aprendizagem da LE, porque o aluno pode visualizar o gênero na realidade e produzi-lo, de acordo com as características composicionais e o estilo. Na produção da proposta de atividade, é sempre importante considerar o interlocutor e a finalidade do texto.

Com relação ao segundo aspecto investigado, o modo como os gêneros são abordados no livro didático Planet $A 1$, as análises demonstraram que dois gêneros, por estarem inseridos na esfera pedagógica, sofreram alterações, que não alteraram o gênero em sua identidade, mas lhe deram outra funcionalidade (MARCUSCHI 2008). Por isso, 
Limberger / Barbosa - Gêneros do discurso no livro didático

alguns dos gêneros não pareceram muito autênticos e os aspectos sintáticos e semânticos foram priorizados, como demonstraram análises de trabalhos precedentes.

Muitas vezes, as situações de comunicação não são apresentadas no livro didático, e as características composicionais não são abordadas. Os textos fazem parte da realidade social e da esfera pedagógica de ensino de LE, na qual essas características de apagamento das questões históricas e socioculturais são frequentes. O professor pode recuperar essas características, de modo que o gênero seja trabalhado de uma forma que se aproxime mais à realidade sócio-histórica. Quando há essa lacuna no livro didático, o professor pode trazer textos com todas as características e compará-los, recuperando, assim, algumas pistas de constituição da situação de comunicação, pois, "o sucesso da missão de introduzir o aluno na língua viva e criativa do povo exige, é claro, uma grande quantidade e diversidade de formas e métodos de trabalho" (BAKHTIN 2013: 43). Portanto, é aconselhável que o professor trabalhe de forma crítica com o livro didático, não somente com relação aos gêneros discursivos. Em outras palavras, acreditamos que é mais produtivo ao ensino de línguas que o professor adapte as atividades do livro didático à situação sociocomunicativa em que se insere, avaliando a necessidade de reorganização das propostas apresentadas no livro com vistas a contribuir com o desenvolvimento da competência comunicativa dos alunos.

\section{Referências bibliográficas}

ANTUNES, Irandé. Análise de textos: fundamentos e práticas. São Paulo, Parábola Editorial, 2010.

ARANTES, Poliana Costi C. Abordagens de Gêneros Textuais veiculados em livros destinados a aprendizes de LE em Língua Alemã. In: VI Simpósio Internacional de Estudos dos Gêneros Textuais, Natal, 2011.

BAKHTIN, Mikhail. Estética da criação verbal. Trad. Paulo Bezerra. São Paulo, Martins Fontes, 2003.

BAKHTIN, Mikhail. Questões de estilística no ensino da língua. Trad. Sheila Grillo e Ekaterina Américo. 1. ed. São Paulo, Editora 34, 2013.

BAKHTIN, Mikhail (VOLOCHÍNOV, V. N.). Marxismo e filosofia da linguagem: problemas fundamentais do método sociológico na ciência da linguagem. Tradução do francês por Michel Lahud e Yara F. Vieira. 4. ed. São Paulo, Hucitec, 2004.

BRAIT, Beth. Apresentação - Importância e necessidade da obra O método formal nos estudos literários: introdução a uma poética sociológica. In: MEDVEDIÉv, P. N. O método formal nos estudos literários: introdução crítica a uma poética sociológica. Tradução de Ekaterina Vólkova Américo e Sheila Camargo Grillo. São Paulo, Contexto, 2012, 11-17. 
BRASIL. Ministério da Educação, Secretaria de Educação Fundamental. Parâmetros Curriculares Nacionais: Língua Estrangeira - Terceiro e quarto ciclos do Ensino Fundamental. Brasília, MEC/SEF, 1998.

- Ministério da Educação, Secretaria de Educação Fundamental. Parâmetros Curriculares Nacionais: língua portuguesa - Terceiro e quarto ciclos do Ensino Fundamental: Brasília, MEC/SEF, 1997.

CONSElHO DA EUROPA. Quadro Europeu Comum de Referência para as Línguas Aprendizagem, ensino, avaliação. Porto, Edições ASA, 2001.

JerôNIMO, Gislaine/ BARbOZA, Letícia/ RIBEIRo, Kelli. Gêneros discursivos e autenticidade textual no ensino de língua estrangeira: uma análise de livros didáticos. In: Cadernos do IL, Porto Alegre, n. 46, 2013, 91-106.

KOPP, Gabriele; BÜTTNER, Siegfried. Planet 1 - Deutsch für Jugendliche. Kursbuch. Ismaning, Editora Hueber, 2004a.

. Planet 1 - Deutsch für Jugendliche. Lehrerhandbuch. Ismaning, Editora Hueber, 2004b.

MAIJALA, Minna. Was ein Lehrwerk können muss - Thesen und Empfehlungen zu Potenzialen und Grenzen des Lehrwerks im Unterricht Deutsch als Fremdsprache. In: Info DaF, v. 34, n. 6, 2007, 543-561.

MARCUSCHI, Luiz Antônio. Produção textual, análise de gêneros e compreensão. São Paulo, Parábola Editorial, 2008.

RoDRIGUES, Rosângela Hammes. Análise de gêneros do discurso na teoria bakhtiniana: algumas questões teóricas e metodológicas. In: Linguagem em (Dis)curso, Tubarão, v. 4, n. 2, 2004, 415-440.

RoJo, Roxane. Gêneros do Discurso e Gêneros Textuais: Questões Teóricas e Aplicadas. In: Meurer, José L. /Bonini, Adair / MotTA-Roth, Désirée. (orgs.). Gêneros: teorias, métodos e debates. São Paulo, Parábola Editorial. 2005, 184-207.

SoUZA, Geraldo T. Introdução à teoria do enunciado concreto do círculo de Bakhtin/Volochínov/Medevdev. São Paulo, Humanitas/FFLCH/USP, 1999.

STRIQUER, Marilúcia dos Santos D. O gênero do discurso no livro didático. In: Revista Travessias, v. 3, n. 2, 2009.

Recebido em 01/03/2015

Aceito em 20/08/2015 


\section{Anexos}

\section{Anexo 1}

\section{Telefongespräch}

A Manuel Altmann.

- Hallo, Manu! Hier ist Uli.

$\Delta$ Hallo, Uli. Was gibt's denn?

Kommst du mit ins Kino?

$\Delta$ Tut mir leid. Ich kann nicht.

- Warum denn nicht?

$\Delta$ Erst muss ich hier sauber machen und Geschirr spülen. Dann muss ich den Müll rausbringen, ...

- Ach, komm schon! Der Film läuft nur heute. Und er ist bestimmt ganz toll.

$\Delta$ Es geht aber heute wirklich nicht!

Nun sei kein Frosch!

$\Delta$ Also gut! Aber ich muss um fünf Uhr zu Hause sein.

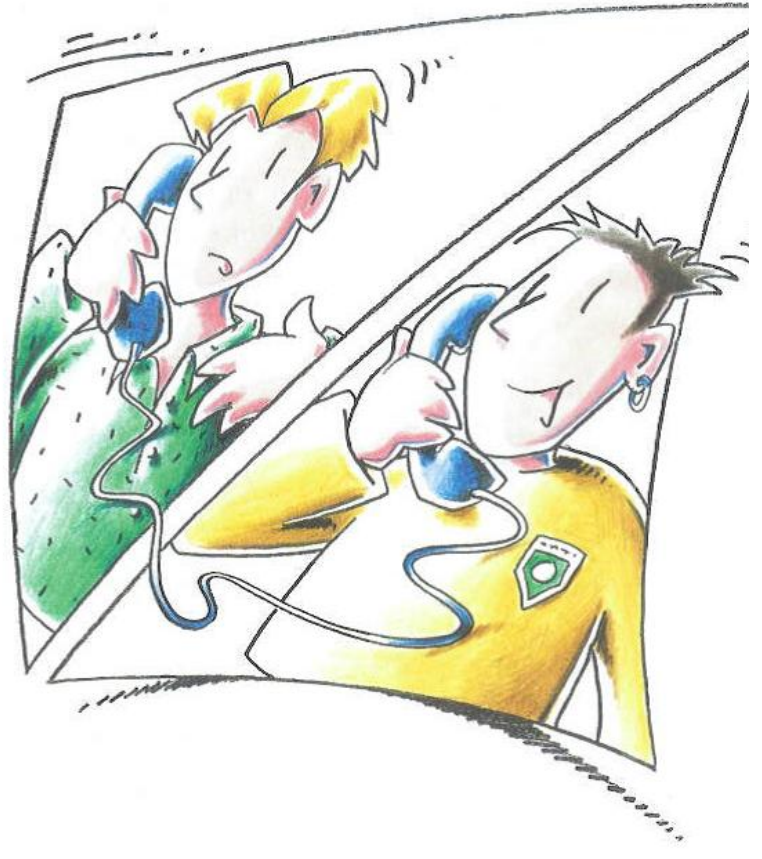

\section{Tipp!}

Lern Redewendungen auswendig und verwende sie auch in anderen Situationen.

a) Und auch so:

\begin{tabular}{l|ll}
\hline in den Zirkus & - Ich habe zwei Karten. & - Nun hab dich nicht so! \\
& Aber mein Bruder kann nicht. & \\
auf den Sportplatz & $\begin{array}{l}\text { - Heute ist doch das Spiel gegen } \\
\text { die } 8 \text { b. Und Peter ist krank. }\end{array}$ & - Nun komm schon! \\
ins Schwimmbad & $\begin{array}{l}\text { - Meine Eltern möchten dich } \\
\text { einladen. }\end{array}$ & - Ach, komm schon. \\
zu Paul & $\begin{array}{l}\text { Er hat einen super Videofilm. } \\
\text { Den muss er aber heute zurückgeben. }\end{array}$ &
\end{tabular}

b) Wohin möchtest du deinen Freund / deine Freundin mitnehmen? Macht weitere Dialoge.

Fonte: Planet 1 (KOPP/ BÜTTNER 2004a: 98) 


\section{Anexo 2}
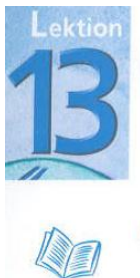

9 Frühstück in aller Welt

a) Beantworte die Fragen:

1 Wie heißt das Mädchen aus Italien?

2 Was frühstückt der Junge aus Neuseeland?

3 Wer trinkt zum Frühstück Kakao?

4 Sie isst zum Frühstück Cornflakes. Woher kommt sie?

b) Mach weitere Fragen für deinen Parłner.

c) Was isst und trinkst du zum Frühstück? Wie frühstücken andere Leute in deinem Land?
Von:Jessi.ca.@ofir.dk, Jessica betreff: Frühstück

Hallol Ich heiße Jessi, bin 15 Jahre alt und Hallol ch häne ich komme aus Dänemark. Moder Brot. Ich trinke Cornflakes, Haferflocken

Fonte: Planet 1 (KoPP/ BÜTTNER 2004a: 94)

\section{Anexo 3}

\section{Landeskunde}

Was machen deutsche Jugendliche in der Freizeit?

a) Schau die Grafik an und mach Sätze. Jungen: $62 \%$ (Prozent) sehen gern fern.

$34 \%$ machen ...

?\% surfen gern im Internet.

Mädchen:

$67 \%$ treffen sich gern mit Leuten.

$32 \%$ lesen ...

? \% spielen am Computer.
Von:maasots@hotmail.com, Matthew betreff: zum fruehsłück

Hallo, ich heiße Matthew und ich bin 14 .

Ich wohne in Wellington, Neuseeland.

Morgens esse ich Cornflakes mit Zucker und Milch. Ich esse auch Toast mit Honig oder Marmelade. Ich trinke Milch. Am Morgen habe ich einen ziemlich großen Hunger.

betroff:_uli_stortissa@msn.com

betreff: zum fruehstück

Zum Frühstück esse ich nicht viel ... Ich trinke

Kekse. Das ist alles.

Tschüs, Beatrice aus Mailand

b) Schau genau. Was machen Mädchen und Jungen gleich gern?

Was machen Mädchen gern, Jungen aber nicht so gern?

Was machen Jungen gern, Mädchen aber nicht so gern?

c) Frag deinen Partner:

Was machen die Mädchen/Jungen lieber, ... oder ... ?

Was machen die Mädchen/Jungen am liebsten? / gern? / nicht so gern?

d) Macht eine Stafistik in der Klasse. Ihr könnt auch eine Umfrage in der ganzen Schule machen und dann eine Statistik erstellen.

Fonte: Planet 1 (KOPP/ BÜTTNER 2004a: 86) 